\title{
EVALUATION OF EFFECT OF THE FLEXIBLE SHEAR CONNECTOR TYPE EMBEDDED IN HIGH AND NORMAL STRENGTH CONCRETE ON LOAD-SLIP RELATIONSHIP
}

\author{
Shaho Mahmoud Hama ${ }^{1}$, Khalil I. AziZ and Shamil K. Ahmed \\ College of Engineering, University of Anbar-Iraq
}

(Accepted for Publication: December 8 2020)

\begin{abstract}
Shear connectors resists shear force that developed between interface of concrete and steel and then prevent pull - out failure. Stud shear connectors are commonly used and most of research focused on behavior of this type. It's useful to study behavior and efficiency of other types. This investigation is about the effect of different parameters on load-slip and stiffness of flexible shear connectors. Three parameters were considered in this investigation; strength of concrete ( 35.5 and $62 \mathrm{MPa}$ ); type of connector (stud, $\mathrm{C}$-shape and L-shape) and type of connection between shear connectors and steel section. It was found that increasing the compressive strength led to decrease in slip while load increasing. Stiffness of connectors increased with increasing of compressive strength. The stud connectors found to be stronger than $\mathbf{C}$-shape and $\mathbf{L}$-shape connectors while $\mathbf{C}$-shape is the weakest one. Finally using welding connection gave a higher load, lower slip and higher stiffness compared to epoxy regardless of type of connectors and strength of concrete.
\end{abstract}

KEYWORDS: Composite structure; Connectors; Push-out test; Slip; Stud

\section{INTRODUCTION}

$\mathbf{T}$ he performance of composite beams depends on an effective transfer of shear stress at the interface between the steel beam and the concrete slab. Although there is some shear transfer by bond and friction, it cannot be depended upon at high loads as that will destroy such a bond and cause a separation of concrete slab from steel beam. The necessary connection between the steel and concrete components of a composite beam is provided by shear connectors which required to transmit the horizontal shear force and resist the slip i.e. horizontal movement between concrete slab and steel beam. Shear connectors also serve the function of holding the slab down onto the steel beam. For most connectors used in practice, failure by vertical separation is unlikely and any uplift would have only negligible effect on the behavior of the composite beam [Johnson 1975].

The deformation of the flexible shear connectors, such as headed stud and channels, is greater than rigid type, which will appear before failure. The benefits of this type are to resists shear that developed between interface of two materials concrete and steel, and the head prevent pull - out failure. Oehlers [1989] analyzed the shear flow at the interface because of shear connector using direct shear test, the effect of transverse reinforcement was investigated. According to the tests results, the slip at interface decreased in the case of presence of a transverse reinforcement and increased the interaction between concrete slab and steel beam. Lloyd and Wright [1990] determined the 
ultimate strength and corresponding slip of headed shear connectors and profiled steel sheets using static push-out test. Results showed that ultimate strength of connections fell below the current design code values. While Shim et al. [2004] investigated about strength of large shear stud connectors and provided conservative values for their strength. An and Cederwall [1996] investigated the effect of type of concrete and strength on strength of stud connectors. The results showed significantly effects of compressive strength on studs strength. Besides the transverse reinforcement in concrete slab has a negligible effect with using high strength concrete. Bezerra et al [2018] investigated the behavior of a new type of truss-shape shear connectors as an alternative of stud bolt connectors for special issues using push out test. This type of connectors showed good plastic deformations and according to push-out test can be classified as flexible shear connectors. Gautam et al [2019] showed that the slip values of the test composite small box girder steel-concrete beams are inversely proportional to the degree of interaction of shear connection, higher degree of interaction led to smaller maximum value of measured slip. Han et al [2015] evaluated the ultimate slip, load-slip relationship and bearing capacity of shear studs connectors embedded into elastic concrete by testing eighteen push-out specimens. In order to produce elastic concrete, rubber was adding to concrete by $0 \%, 5 \%, 10 \%$ and $15 \%$. The ductility, bearing capacity of studs was improved with increasing rubber contents. Aziz et al. [2018] investigated the effect of plastic fibers on load deflection of bolt stud connections. They found that plastics fibers made the behavior more ductile. Pathirana et al [2016] recommended depending on experimental and numerical analysis the ability of using blind bolts in composite structure to achieve and maintain the composite action between steel and concrete in composite beams under flexural loading. Because of importance of shear connectors in composite structure, many researchers try to study the behavior of shear connectors and most of these research focused on behavior of stud shear connectors. It is useful to study behavior and efficiency of other types. This investigation is about study the behavior of different type of shear connectors. Three parameters were considered in this investigation; strength of concrete (35.5 and $62 \mathrm{MPa}$ ); type of connector (stud, C-shape and L-shape) and type of connection between shear connectors and steel section.

\section{MATERIALS, MIXES PROPORTIONS AND SPECIMENS TESTS}

Type I Cement was used to cast all specimens and its properties satisfied the Iraqi specifications for ordinary cement No.5/1984. Sand with S.G. (specific gravity) 2.58 and sulfate content about $0.45 \%$ was used as fine aggregate, and corresponding sieve analysis is shown in Table 1. Crushed gravel with S.G. (specific gravity) 2.7 and sulfate content about $0.08 \%$ was used as coarse aggregate and corresponding sieve analysis is shown in Table 1. Both types of aggregate properties satisfied the Iraqi Specifications No.45/1984. 
Table (1): \% passing according of sand and crushed gravel according to sieve analysis

\begin{tabular}{ccc}
\hline Sieve size $(\mathbf{m m})$ & \%passing of sand & \%passing of crushed gravel \\
\hline 14 & - & 100 \\
\hline 10 & 100 & 84 \\
\hline 5 & 91 & 34 \\
\hline 2.36 & 72 & 10.5 \\
\hline 1.18 & 58 & 0.75 \\
\hline 06 & 35 & - \\
\hline 0.3 & 13 & - \\
\hline 015 & 3 &
\end{tabular}

Epoxy glue and welding were used to connect the shear connectors with steel section. Three shapes of shear connectors are used (Figure 1); - Stud connector: The diameter of the head for this type was $(20 \mathrm{~mm})$ with height $(35 \mathrm{~mm})$, and of the bar was used diameter $(10 \mathrm{~mm})$ with yield strength of $600 \mathrm{MPa}$ and ultimate strength of
750MPa.

- L-shape: The width of flange of this type was $(20 \mathrm{~mm})$ with height $(35 \mathrm{~mm})$ and $\mathrm{f}_{\mathrm{y}}^{\prime}=600 \mathrm{MPa}$ and $\mathrm{f}_{\mathrm{u}}=750 \mathrm{MPa}$.

- C-shape: The width of flange of this type was $(20 \mathrm{~mm})$ with height $(35 \mathrm{~mm})$ and $\mathrm{f}_{\mathrm{y}}^{\prime}=600 \mathrm{MPa}$ and $\mathrm{f}_{\mathrm{u}}=750 \mathrm{MPa}$.

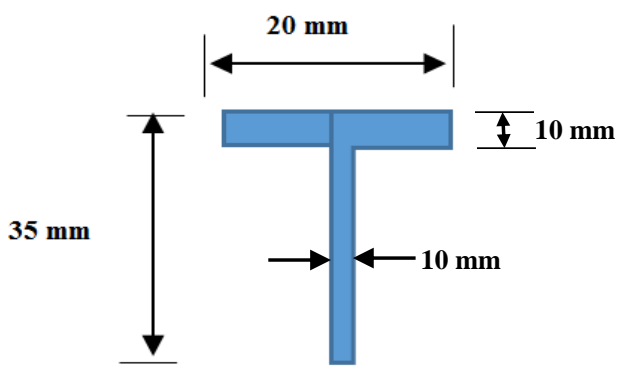

Stud connector

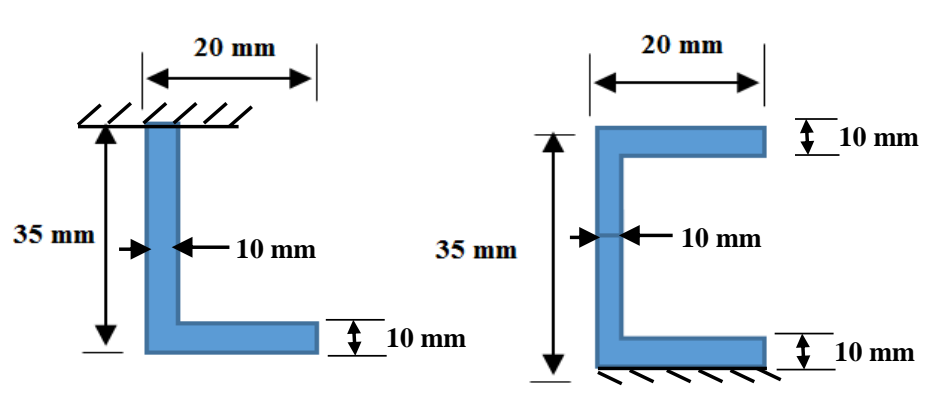

L-shape connector

C-shape connector

Fig. (1): Types of connectors used in this investigation

The mix proportions for the mixes are listed in Table 2. For each mix compressive strength was measured according to ASTM C39-03. Push-out specimens have been made according to Euro code 4. The push-out specimen consists of two small concrete slabs where are linked to the flanges of $\mathrm{M} 4 \times 3.45$ section by 4 -connecters for each side, Figure 2 . The specimens have been fabricated according to the dimensions of using connectors. For specimens test, a $2000 \mathrm{kN}$ capacity hydraulic testing machine was used. Concrete slabs parts were embedded in lower of testing machine while the load was applied gradually to top end of steel section, Figure 2. Loads and corresponding slip were recorded. 
Table (2): Concrete mix proportions

\begin{tabular}{|c|c|c|c|c|c|c|}
\hline Type of mix & $\begin{array}{c}\text { Cement } \\
\mathrm{kg} / \mathrm{m}^{3}\end{array}$ & $\begin{array}{l}\text { Silica fume } \\
\mathrm{kg} / \mathrm{m}^{3}\end{array}$ & $\begin{array}{l}\text { Sand } \\
\mathrm{kg} / \mathrm{m}^{3}\end{array}$ & $\begin{array}{l}\text { Gravel } \\
\mathrm{kg} / \mathrm{m}^{3}\end{array}$ & $w / c$ & $\begin{array}{c}\mathrm{Sp} \% \text { (as } \\
\text { percentages of } \\
\text { cement content) }\end{array}$ \\
\hline $\begin{array}{l}\text { Normal-strength } \\
\text { concrete }\end{array}$ & 400 & - & 600 & 1200 & 0.42 & - \\
\hline High-strength concrete & 360 & 40 & 600 & 1200 & 0.32 & 0.85 \\
\hline
\end{tabular}
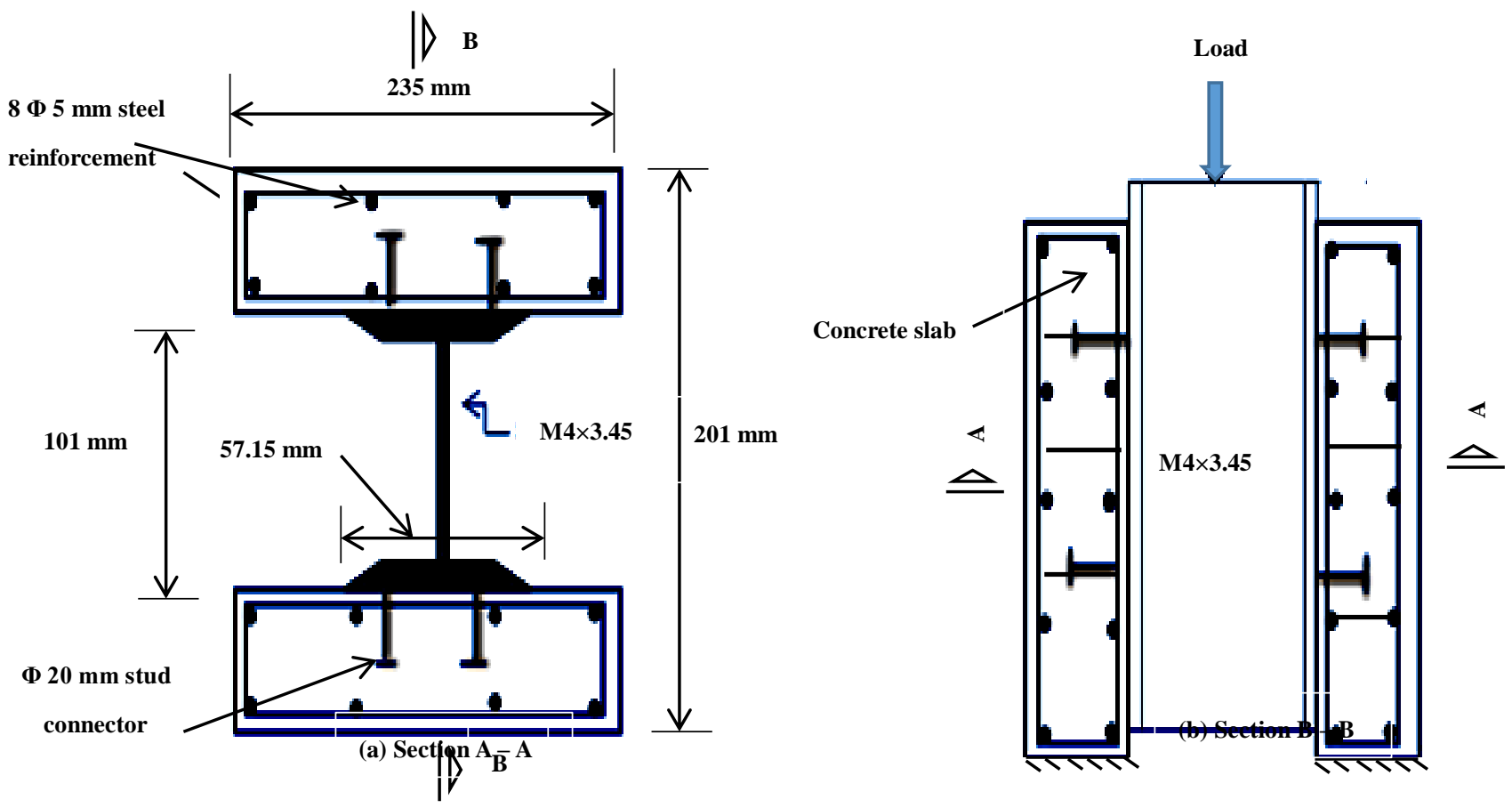

Fig. (2): Dimension of push-out specimens and loading procedures

\section{RESULTS AND DISCUSSIONS}

The test results were recorded and listed in Table 3 and graphically in Figure 3 and 4. Shear stiffness for connectors was calculated according to following equation

$$
\mathrm{Ks}=\frac{0.5 * P_{u}}{\operatorname{Slip}}
$$

Where $\mathrm{K}_{\mathrm{s}}=$ shear stiffness of connectors, $\mathrm{kN} / \mathrm{mm}$ $\mathrm{P}_{\mathrm{u}}=$ ultimate recorded load before failure, $\mathrm{kN}$ 
Table (3): Experimental results

\begin{tabular}{|c|c|c|c|c|c|c|}
\hline $\begin{array}{l}\text { Type of } \\
\text { concrete }\end{array}$ & $\begin{array}{l}\text { Compressive } \\
\text { strength MPa }\end{array}$ & $\begin{array}{l}\text { Method of fixing the } \\
\text { connector with steel } \\
\text { section }\end{array}$ & Type of connectors & Slip (mm) & $\begin{array}{l}\text { Ultimate } \\
\text { load (kN) }\end{array}$ & $\mathrm{Ks}(\mathrm{kN} / \mathrm{mm})$ \\
\hline \multirow{6}{*}{$\begin{array}{l}\text { Normal } \\
\text { strength } \\
\text { concrete }\end{array}$} & 35.5 & welding & Stud & 2.5 & 49 & 9.8 \\
\hline & & & C-shape & 2.8 & 41 & 7.3 \\
\hline & & & L-shape & 1.8 & 29 & 8.06 \\
\hline & & epoxy & Stud & 7.4 & 59 & 3.99 \\
\hline & & & C-shape & 8.4 & 42 & 2.5 \\
\hline & & & L-shape & 4.2 & 32 & 3.8 \\
\hline \multirow{6}{*}{$\begin{array}{l}\text { High strength } \\
\text { concrete }\end{array}$} & 62.0 & welding & Stud & 2.15 & 69 & 16.04 \\
\hline & & & C-shape & 1.85 & 50 & 13.5 \\
\hline & & & L-shape & 1.54 & 44 & 14.28 \\
\hline & & epoxy & Stud & 6.2 & 48 & 3.9 \\
\hline & & & C-shape & 7.4 & 42 & 2.84 \\
\hline & & & L-shape & 5 & 38 & 3.8 \\
\hline
\end{tabular}

The parameters that considered in these investigations are

1. Strength of concrete (35.5 and $62 \mathrm{MPa})$

2. Type of connector (stud, C-shape and L-shape)

3. Type of connection between concrete and steel section

\subsection{Effect of concrete strength}

From Figures 3 and 4, it can be seen that with increasing the compressive strength the slip decrease and the load are increasing. While stiffness increased with increasing of the compressive strength, as shown in Table 3 and Figure 5. The results is reasonable since increasing the compressive strength of concrete results in a more brittle behavior which mean the specimens fails in higher loads and lower slip or deformation.

\subsection{Effect of type of connector}

The stud connectors seem to be able to resist more load than $\mathrm{C}$-shape and L-shape connectors, Table 3 and Figures 3 and 4. But C- shape recorded higher slip and lower load at failure compared to other two type. The stud connectors has the highest stiffness while $\mathrm{C}$-shape the lowest as shown in Figure 5.

\subsection{Effect of type of connection between connectors and steel section}

From results in Table 3 and Figure 3 and 4 show that using welding as connection gave a higher load a lower slip and higher stiffness compared to epoxy regardless of type of connectors and strength of concrete as shown in Figure 56. 


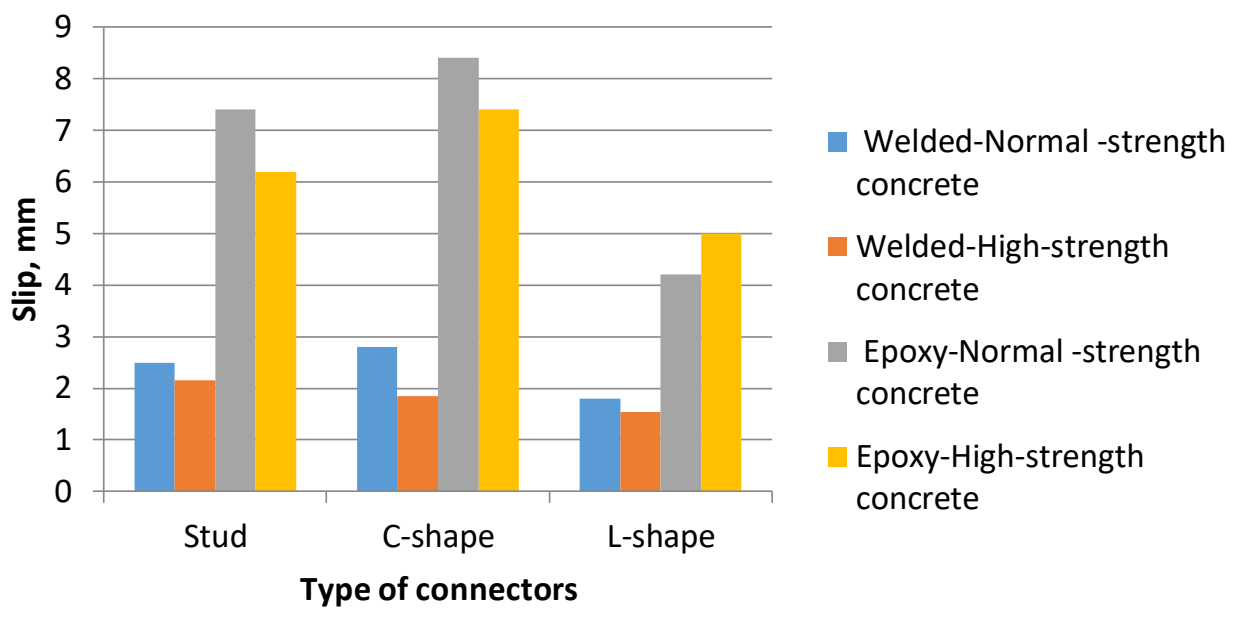

Fig. (3): Slip displacement verse type of connectors for tested specimens
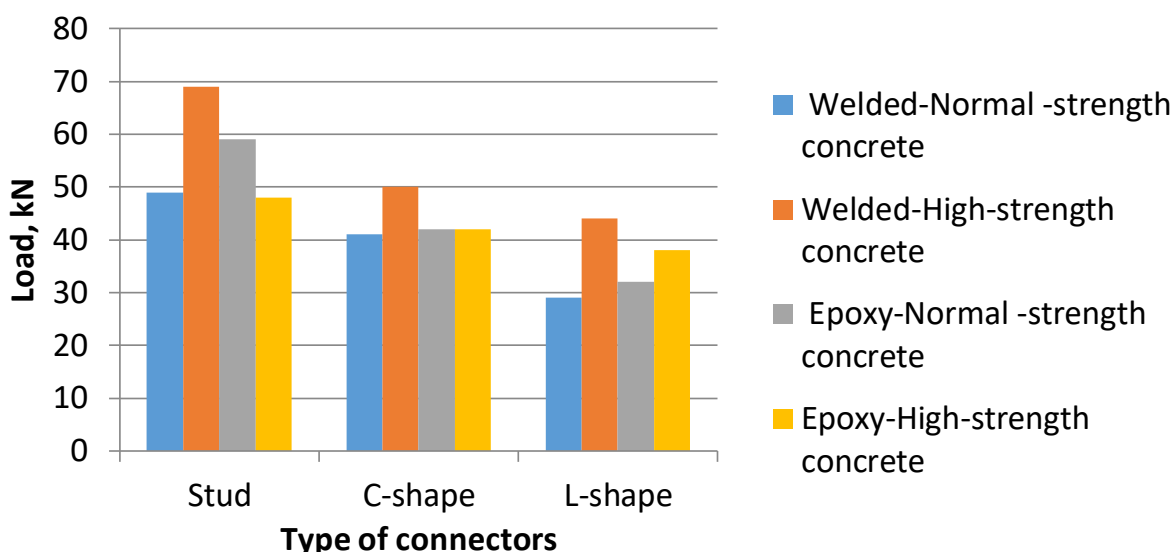

Type of connectors

Fig (4): Ultimate recorded load verse type of connectors for tested specimens

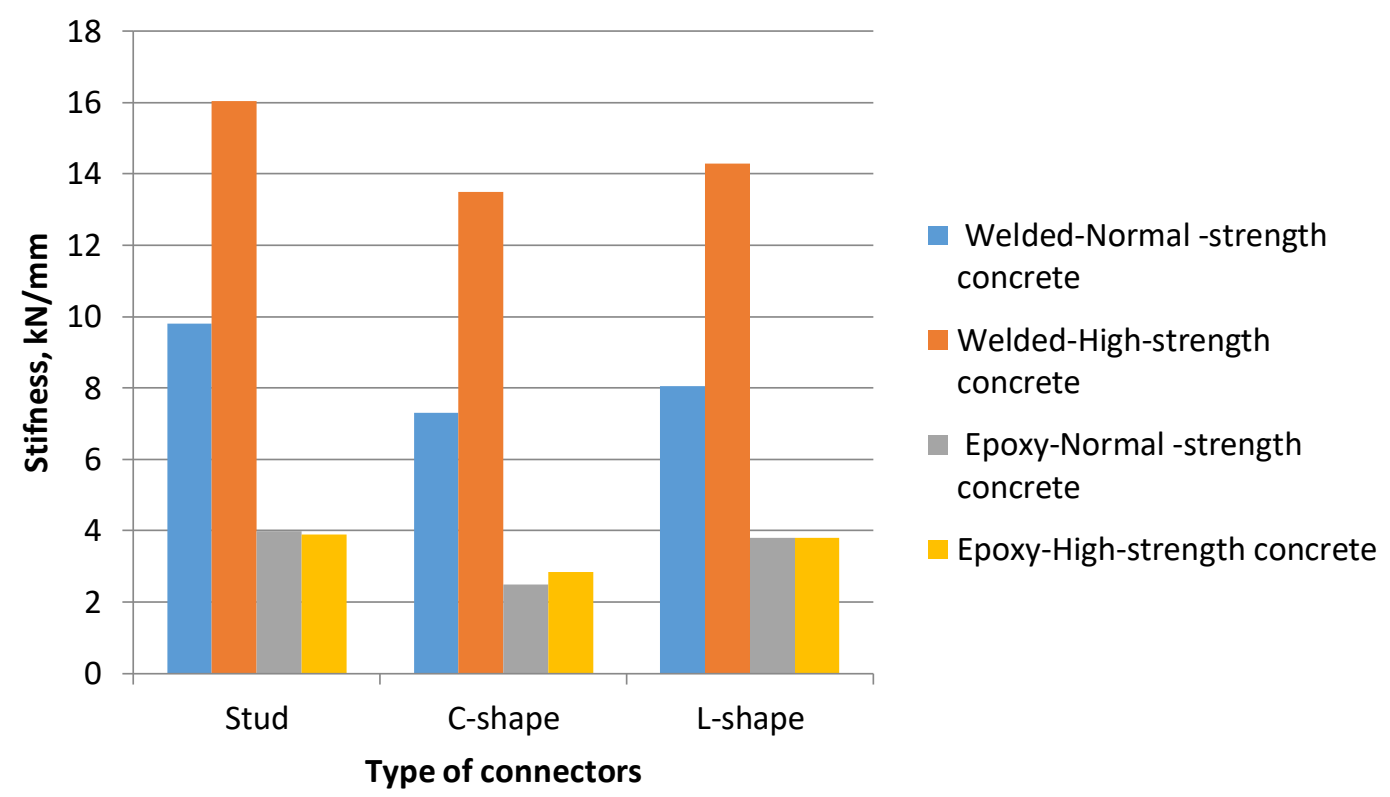

Fig. (5): Stiffness of connectors verse type of connectors for tested specimens 


\section{CONCLUSIONS}

The following conclusions can be drawn form the conducted study:

1. From the results of this investigation the following conclusion are made.

2. Increasing the compressive strength led to decrease in slip while load increasing.

3. Stiffness of connectors increased with increasing of compressive strength.

4. The stud connectors found to be more strong than C-shape and L-shape connectors while $\mathrm{C}$-shape was the weakest one.

5. Using welding as connection gave a higher load a lower slip and higher stiffness compared to epoxy regardless of type of connectors and strength of concrete.

\section{REFERENCE}

ASTM: C39, (2005), "Compressive Strength of Cylindrical Concrete Specimens", American Society of Testing and Material International.

An Li and Cederwall Krister (1996) Push-out Tests on Studs in High Strength and Normal Strength Concrete. Journal of Constructional Steel Research. 36(1):15-29

Aziz K. I., Hama S. M., . Kuhair H. M (2018). Efficiency of Waste Plastic Fiber on Behavior of Composite Steel Plate- Concrete Push Out Test" 11th International Conference on Developments in eSystems Engineering (DeSE). 335-339. DOI 10.1109/DeSE.2018.00066

Bezerra Luciano M., Barbosa Wallison C.S., Bonilla J., Cavalcante Otávio R.O. (2018). Truss-type shear connector for composite steel-concrete beams. Construction and Building Materials. 167:

757-767.

https://doi.org/10.1016/j.conbuildmat.2018.01. $\underline{183}$

European Committee for Standardisation (CEB), Eurocode 4 (1994). Design of Composite Steel and Concrete Structures", Part 1.1: General
Rules and Rules for Buildings, DD ENV 1994-1-1, EC4

Gautam B. G., Xiang Y., Liao X., Qiu Z. and Guo S. (2019). Experimental Investigation of a Slip in High-Performance Steel-Concrete Small Box Girder with Different Combinations of Group Studs. Materials 2019, 12, 2781; doi:10.3390/ma12172781

Han Q., Wang Y., Xu J., Xing Y. (2015). Static behavior of stud shear connectors in elastic concrete-steel composite beams. Journal of Constructional Steel Research. 113 (2015) 115-126.

http://dx.doi.org/10.1016/j.jcsr.2015.06.006

Iraqi specification No.6/29-1984 Portland Cement Central Agency for Standardization and Quality Control, Planning Council, Baghdad, Iraq, translated from Arabic edition.

Iraqi specification No.46/2984, "Aggregate from Natural Sources for Concrete", Central Agency for Standardization and Quality Control, Planning Council, Baghdad, Iraq, translated from Arabic edition.

Johnson, R. P. (1975). Composite Structures of Steel and Concrete, Volume 1. beams, columns, frames, applications in building", Crosby Lockwood Staples, London. pp. 210.

Lloyd R M, Wright H D. (1990) Shear connection between composite slabs and steel beams. Journal of Structural Engineering.15(4):25585.

Oehlers DJ. (1989). Splitting induced by shear connectors in composite beams. Journal of Structural Engineering 1989;115(2):341-62. http://dx.doi.org/10.1061/(ASCE)0733-9445(1 989) 115:2(341).

Pathirana S. W., Uy B., Mirza O., Zhu X.. Flexural behaviour of composite steel-concrete beams utilising blind bolt shear connectors. Engineering Structures 114 (2016) 181-194. http://dx.doi.org/10.1016/j.engstruct.2016.01.0 $\underline{57}$

Shim CS, Lee PG, Yoon TY. (2004). Static behaviour of large stud shear connectors. Journal of Engineering Structure 2004;26(12):1853-60. 